\title{
Flowability Assessment of Fine Coals Based on Dynamic Properties ${ }^{\dagger}$
}

\author{
Keijiro Terashita and Kei Miyanami \\ Department of Chemical Engineering \\ University of Osaka Prefecture* \\ Takanobu Konishi \\ Hosokawa Micron Corp. ** \\ Kazuo Furubayashi \\ Kawasaki Heavy Industry Co., Ltd. ***
}

\begin{abstract}
Flowability assessment of dry and wet fine coals has been attempted on the basis of their dynamic properties such as internal friction factor, shearing cohesiveness and tensile strength. The dynamic parameters have been determined by using a constantload direct shearing tester and a hanging-type split-cell cohesiveness tester. Several kinds of coals with different water contents have been used.

The flowability of brown coal is highest with low values of the internal friction factor, shearing cohesiveness and tensile strength. The ranking of flowability is in order of bituminous coal and semi-bituminous coal. The flowability of anthracite is high. The flowability of fly ash is higher when compared to fine coals but it is easily influenced by a slight change in the water content.

The flowability of wet fine coals can be better evaluated by the tensile strength and shearing cohesiveness rather than by the internal friction factor. The tensile strength of wet fine coals shows a maximum when a comixture of funicular and capillary zones in formed. The flowability of wet fine coals is controlled by water adsorbed onto the surface of coal particles.
\end{abstract}

\section{Introduction}

Coal once replaced by oil is recognized anew as a substitute source of energy. The needs of the present time have stimulated extensive studies and developments of liquefaction, gasification and efficient combustion of coal.

* 4-804, Mozu-Umemachi, Sakai, Osaka, 591 TEL. 0722 (52) 1161

** No. 9, 1-chome, Shoudai Tajika, Hirakata-shi, Osaka, 573 TEL. 0720 (55) 2221

*** 1-18, Nakamachi-dori 2-chome, Chuo-ku, Kobe, Hyogo, 650 TEL. 078 (341) 7731

$\dagger$ This report was originally printed in $J$. Soc. Materials Science, Japan, 33, 1130-1134 (1984) and 34, 1249-1254 (1985) in Japanese, before being translated into English with the permission of the editorial committee of the Soc. Materials Science, Japan.
Determination of physical characteristics such as internal friction factor, shearing cohesiveness and tensile strength of coal and fly ash as powder materials provides an exceedingly important key to rational design and smooth operation of combustion processes. Recent studies have described some aspects of the dynamic properties of coal. However, systematic approaches do not yet seem to have been adequately attempted. Despite obvious differences in the physicochemical characteristics of a variety of coals, existing studies seem to have dealt with only a limited range of various coals ${ }^{1-11)}$. In addition, physicochemical characteristics have not been sufficiently compared between coal and fly ash. Adhesion and caking are problems that occur in fine coals rather than in coarse coals. The water content in coal usually increases due to rainfall or the water 
sprinkled for prevention of dust spreading. Evaluation of the dynamic properties of fine coals in a wet state is, therefore, indispensable. Various shear tests have been performed on coals with different water contents. However, flowability studies of fine coals remain insufficient. The tensile strength of wet fine coals has been little reported.

We have earlier reported that the internal friction factors of coarse and fine powders, calculated from the relationship between the measured average vertical stress and stationary shearing stress in the vicinity of shearing plane, are almost free from the effects of experimental conditions ${ }^{12)}$ and that the flowability of powders can be estimated on the basis of the internal friction factor, shearing cohesiveness or pattern of vertical stress distribution in the vicinity of shearing plane ${ }^{13)}$. We have also determined the internal friction factor and tensile strength of wet powders and discussed the problem of flowability ${ }^{14}$ )

In this study, direct shearing tests under a constant load condition and tensile breakup tests of fine powder beds have been carried out by using various kinds of fine coals with different water contents. Comprehensive evaluation of the flowability of fine coals and fly ash has been attempted by examining various parameters (internal friction factor, shearing cohesiveness and tensile strength) in relation to the fuel ratio in the coals. The flowability of wet fine coals has been discussed on the basis of the dynamic properties thus obtained. The results have been compared with those obtained with various other powder samples.

\section{Materials and Methods}

The vertical stress and its distribution in the vicinity of shearing plane were measured by a constant-load, monoplanar shearing tester. This tester is the same as used previously ${ }^{13,14}$. The shearing cell is an important part of the tester and is illustrated in detail in Fig. 1. The shearing stress $\bar{\tau}_{x}$ generated by shearing powder beds (coal or fly ash) was measured by a proving ring and dial gauges. The vertical stresses $\left(\sigma_{z, m^{\prime}}, \sigma_{z, m}\right)$ at six points were simultaneously measured by strain-gauge pressure transducers (sensing zone: $0.006 \mathrm{~m}$ in diameter, capacity: $196.2 \mathrm{kPa}) . \bar{\tau}_{x}$ and vertical displacement $\delta_{z}$ were continuously recorded.

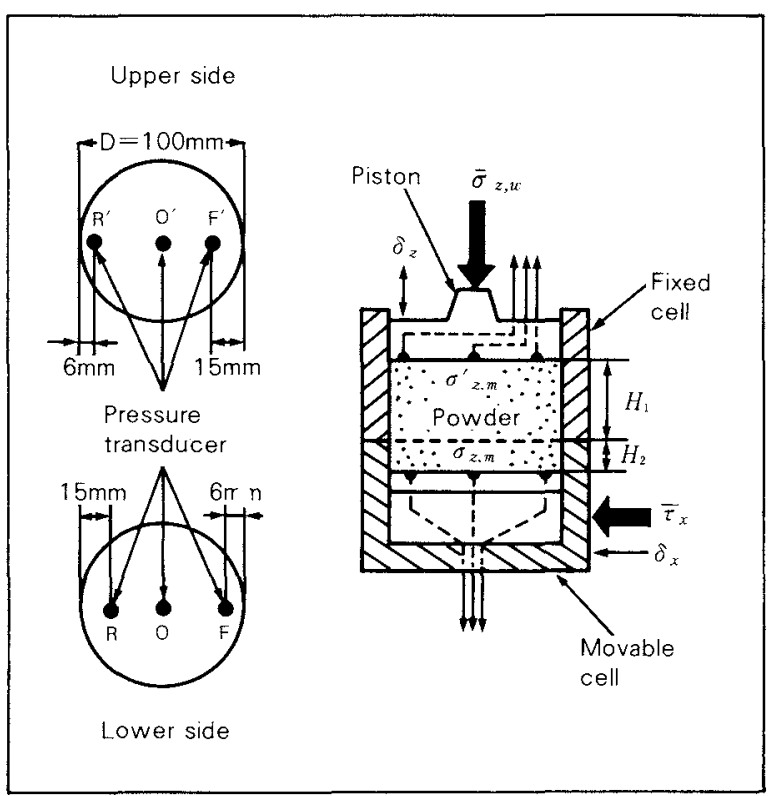

Fig. 1 Layout of pressure transducers in the vicinity of shearing plane

For the measurement of the tensile strength, a hanging-type cohesiveness tester ${ }^{15)}$ was utilized. This tester is a split-cell type that can provide vertical compression and horizontal tension. A movable cell is suspended by three phosphor bronze plates. The inside diameter of the cell measures $0.05 \mathrm{~m}$. The tension velocity is $3.33 \times$ $10^{-5} \mathrm{~m} / \mathrm{s}$. The tester is characterized by its advantage of permitting the determination of the relationship between tensile stress $\bar{\sigma}_{x}$ and horizontal displacement $\delta_{x}$ (this relationship is called tensile breakup process curve in what follows) of powder beds (coals)

The methods of direct shearing test and tensile breakup test have been reported elsewhere $^{13,15)}$

The fine coal samples used in this study have been obtained by sieving unpulverized coal into desired particle sizes ranging from 44 to $74 \mu \mathrm{m}$. Table 1 lists the properties and fuel ratios of various coal samples used. The data in this table are based on JIS M8812. The fuel ratio indicates the ratio of fixed carbon to volatile matter. It is known to increase with coalification $^{16)}$. As coal can be classified by the fuel ratio, the kinds of coal used in this study are expressed in terms of the fuel ratio $(F R)$. The fly ash samples used were fly ash $\mathrm{A}\left(d_{w, 50}=\right.$ $\left.13.6 \mu \mathrm{m}, \sigma_{g}=2.75\right)$, fly ash B $\left(d_{w, 50}=8.8 \mu \mathrm{m}\right.$, $\left.\sigma_{g}=2.35\right)$ and clinker ash. Fly ash A was obtained from Australian coal by combustion in 
Table 1 Proximate analysis of coals

\begin{tabular}{l|c|r|c|c|c}
\hline \multicolumn{1}{c|}{ Coal } & Moisture & Ash & $\begin{array}{c}\text { Volatile } \\
\text { matter }\end{array}$ & $\begin{array}{c}\text { Fixed } \\
\text { carbon }\end{array}$ & $\begin{array}{c}\text { Fuel } \\
\text { ratio }\end{array}$ \\
\hline Japan A & 5.5 & 16.4 & 44.1 & 34.0 & 0.77 \\
Japan B & 1.5 & 8.9 & 42.0 & 47.6 & 1.13 \\
Australia & 3.0 & 13.5 & 30.3 & 53.5 & 1.77 \\
U.S.S.R. A & 3.8 & 12.7 & 19.1 & 64.4 & 3.37 \\
U.S.S.R. B & 1.4 & 7.8 & 20.8 & 70.0 & 3.37 \\
U.S.S.R. C & 1.8 & 8.0 & 15.9 & 74.3 & 4.67 \\
P.R.O.C. A & 0.4 & 0.2 & 13.1 & 86.2 & 6.58 \\
P.R.O.C. B & 1.5 & 16.2 & 8.8 & 73.5 & 8.35 \\
Vietnam & 2.2 & 7.4 & 5.5 & 84.9 & 15.4 \\
\hline
\end{tabular}

a boiler. Fly ash B and clinker ash were obtained likewise from fine Japanese coals $\mathrm{A}$ and $B$ respectively. Clinker ash was used after sieving $\left(d_{p}=-44 \mu \mathrm{m}\right)$.

To adjust the water content in fine coals and powders, the samples were placed in a vertical cylindrical mixer ${ }^{15)}$ into which distilled water was added little by little and mixed homogeneously. The water content in the fly ash samples was adjusted by mixing regularly for 24 hours in a constant-temperature humidifier controlled at a specified humidity. The water content $\phi_{v}$ in these powders was calculated on the weight basis by drying the samples for an hour at $373-383 \mathrm{~K}$. The samples were collected from the cells after the tensile breakup and shearing tests. To avoid changes in the water content during the aging period after humidification, the wet fine powder samples adjusted at specified water contents were stored in a polyvinyl chloride vessel. The water content did not change during two weeks of aging period.

\section{Results and Discussion}

\section{1 Tensile strength, internal friction factor and shearing cohesiveness of powders}

(1) Flowability of fine coal

Figure 2 shows an example of the relationship between the mean actual vertical stress $\bar{\sigma}_{z, m}$, the applied vertical stress $\bar{\sigma}_{z, w}$ and the stationary shearing stress $\bar{\tau}_{x, s}$. The actual vertical stress $\bar{\sigma}_{z, m}$ is the average of vertical stresses $\sigma_{z, m}(m=\mathrm{F}, \mathrm{O}$, and $\mathrm{R})$ measured at three points on the bottom of the powder bed (on the side of movable cell) (Fig. 1) after both the shearing stress $\bar{\tau}_{x}$ and vertical displacement $\delta_{z}$ become stationary ${ }^{12,13)}$. In the case of relatively small vertical load as used in this study, a flow surface of Roscoe's diagram is usually observed and powder yield locus is obtained ${ }^{17,18)}$.

As can be seen from Fig. 2, the $\bar{\sigma}_{z, w}-\bar{\tau}_{x, s}$ relation is convex and deviates from Coulomb's law. $\bar{C}_{w}$ in the figure is a shearing cohesiveness defined by Eq. (1 $)^{19)}$ :

$$
\left(\bar{\tau}_{x, s} / \bar{C}_{w}\right)^{n}=1+\bar{\sigma}_{z, w} / \bar{\sigma}_{x, T}
$$

The values of $\bar{\tau}_{x, s}$ and $\bar{\sigma}_{x, T}$, respectively, should be read from the $\bar{\tau}_{x, s}-\bar{\sigma}_{z, w}$ and $\bar{\sigma}_{x, T}-$ $\bar{\epsilon}_{0}$ relations for the same initial void fraction $\bar{\epsilon}_{0}{ }^{20)}$. On the other hand, the $\bar{\sigma}_{z, m}-\bar{\tau}_{x, s}$ relation is linear, and Coulomb's law holds. Therefore, the internal friction factor $\mu_{m, s}$ and shearing cohesiveness $\bar{C}_{m}$ can be obtained from Eq. (2):

$$
\bar{\tau}_{x, s}=\mu_{m, s} \cdot \bar{\sigma}_{z, m}+\bar{C}_{m}
$$

The value of $\bar{\sigma}_{x, E}$ in Fig. 2, which corresponds to a tensile strength, is obtained by extrapolating the line of Eq. (2) to $\bar{\tau}_{x, s}=0$. It has been experimentally confirmed that the internal friction factor $\mu_{m, s}$, calculated by Eq. (2), is not influenced by the measurement condi-

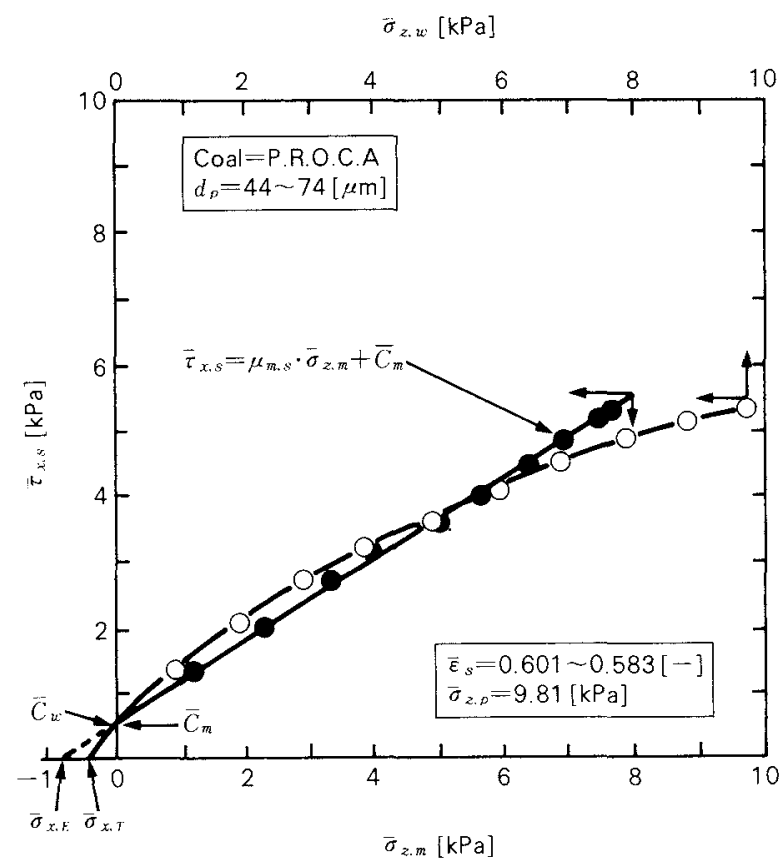

Fig. 2 Relationship between mean values of actual normal stress $\bar{\sigma}_{z, m}$ and stationary shearing stress $\bar{\tau}_{x, s}$, and between applied normal stress $\bar{\sigma}_{z, w}$ and $\bar{\tau}_{x, s}$ 
tions ${ }^{12,13)}$. This implies that $\bar{C}_{m}$ as well as $\bar{\sigma}_{z, E}$ are also not influenced by the diameter of shearing cell and the height of powder bed in the cell. Furthermore, Figure 2 also shows that the mean actual vertical stress $\bar{\sigma}_{z, m}$ is smaller than $\bar{\sigma}_{z, w}$, when the applied vertical stress $\bar{\sigma}_{z, w}$ $\geq 6 \mathrm{kPa}$. This indicates that the load applied onto the upper surface of the powder bed is not totally transmitted to the vicinity of shearing plane and a part of it is supported by the cell wall.

Figure 3 shows the ratio of the mean actual vertical stress $\bar{\sigma}_{2, m}$ to the applied vertical stress $\bar{\sigma}_{z, w}$ in relation to the fuel ratio $F R$ of the coal under a specific measurement condition, for an example. It can be seen that the ratio, $\bar{\sigma}_{z, m} /$ $\bar{\sigma}_{z, w}$, decreases with an increase in $F R$ and reaches a minimum at $F R=6.5$ and then increases with an increase in $F R(>6.5)$. This means that the applied vertical stress is well transmitted to the vicinity of the shearing plane of brown coal (Japan A) and anthracite (Vietnam) but only poorly transmitted for semibituminous coal (China A). Such a difference in the transmission of stress by the fuel ratio (the degree of coalification) suggests the importance of the kind of coal in designing and operation of a combustion installation.

Figure 4 shows the relations between the internal friction factor $\mu_{m, s}$, shearing cohesiveness $\bar{C}_{m}$ and the tensile strength $\bar{\sigma}_{x, E}$ for various fine coal samples as calculated by Eq. (2). The shearing cohesiveness and tensile strength are found to decrease with a decrease in the internal friction factor. Low values of these dynamic parameters mean a high flowability, as judged from actual experiences of handling fine coals. This is consistent with the evaluation based on the flow rate of fine coals through a cone hopper.

The internal friction factor $\mu_{m, s}$ and shearing cohesiveness $\bar{C}_{m}$ (shown in Fig. 4) are plotted against the fuel ratio in Fig. 5. It can be seen that the flowability of brown coal (Japan A) and anthracite (Vietnam) is highest, that of semibituminous coal (China A) lowest, and those of the others in between. Comparing the data in Fig. 5 with those in Fig. 3, one can easily understand that a high flowability of fine coal corresponds to a high transmittancy of the applied vertical stress to the vicinity of shearing plane. This fact also applies to other fine powders ${ }^{13)}$. The increase in the internal friction factor $\mu_{m, s}$ with an increase in $F R$ at $F R<$ 6.5 may be due to an increase in the content of fixed carbon. At $F R>6.5, \mu_{m, s}$ decreases because of a decrease in the content of volatile matter. Phenomenologically, a maximum of

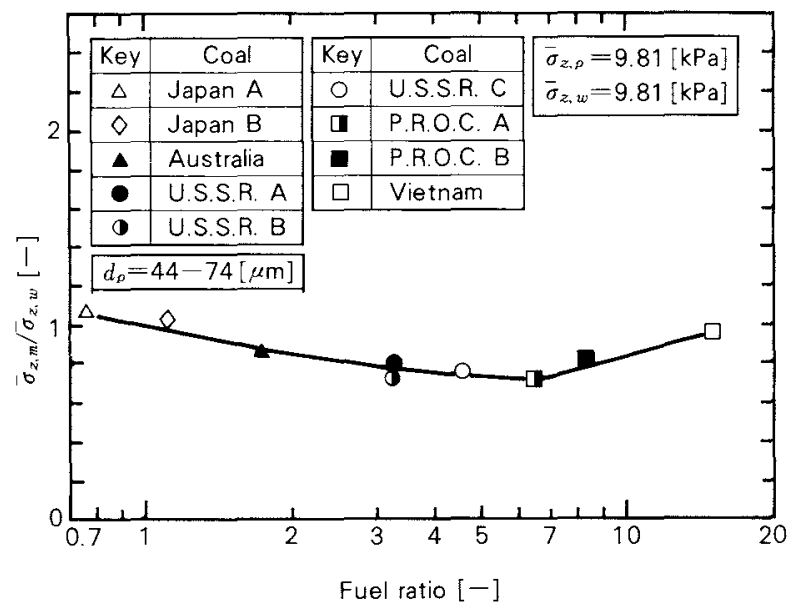

Fig. 3 Relationship between transmission of the applied normal stress and fuel ratio

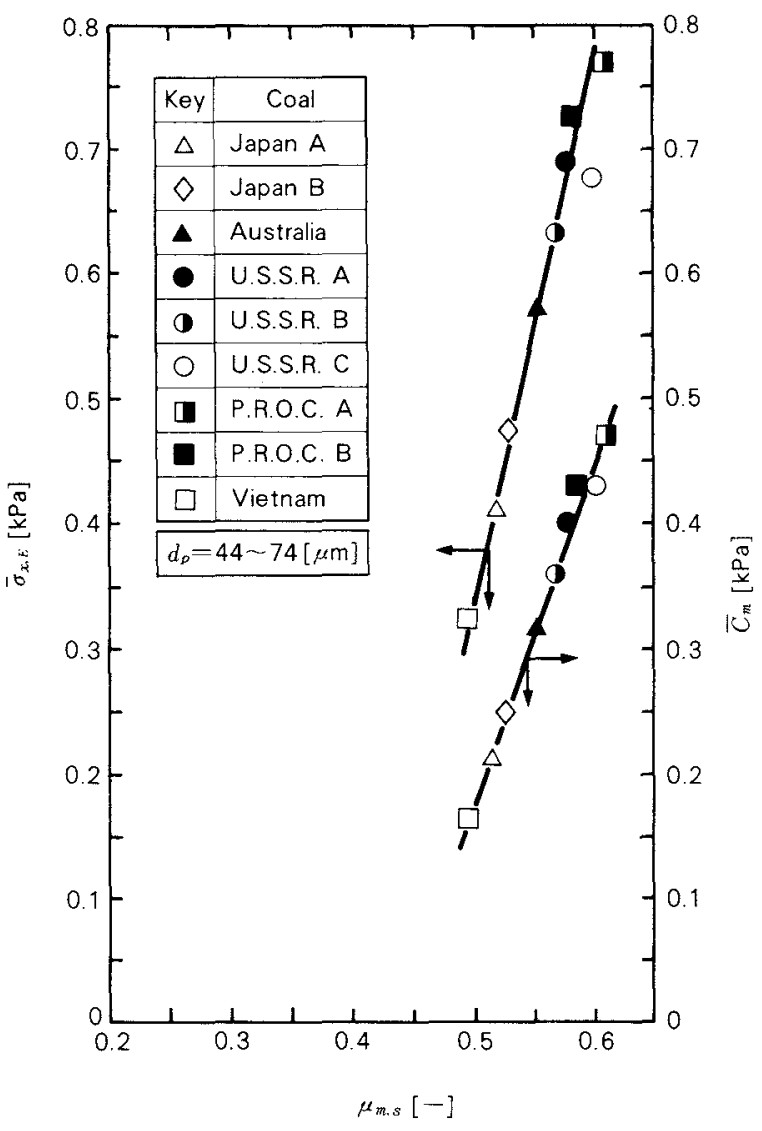

Fig. 4 Internal friction factor $\mu_{m}$, , cohesion force $\bar{C}_{m}$ and tensile strength $\bar{\sigma}_{x, E}$ for several kinds of fine coals 


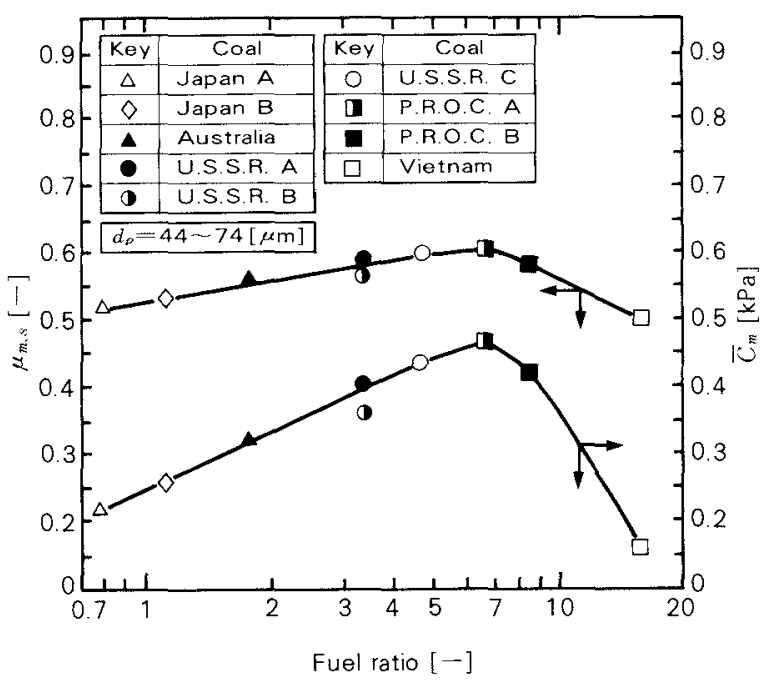

Fig. 5 Relationship among internal friction factor $\mu_{m, s}$, cohesion force $\bar{C}_{m}$ and fuel ratio of fine coals

internal friction factor at a certain fuel ratio (degree of coalification) may correspond to many physicochemical changes in coal particles such as porosity and surface area during coalification at the degree of which is 85 to $95^{16)}$. It has been noted that the parameters $n$ (shear index) and $\bar{C}_{w}$, derived from Eq. (1), cannot be well correlated with the fuel ratio.

Figure 6 shows an example of the tensile breakup test results of fine coals. The tensile strength $\bar{\sigma}_{x, T}$ is plotted against the fuel ratio in this figure. The tensile strength increases with an increase in $F R$ at $F R \leq 6.5$, but decreases with $F R>6.5$. The pattern of $\bar{\sigma}_{x, T}-$ $F R$ relation, as shown in Fig. 6, has not changed even if the range of initial void fraction $\bar{\epsilon}_{0}$ is

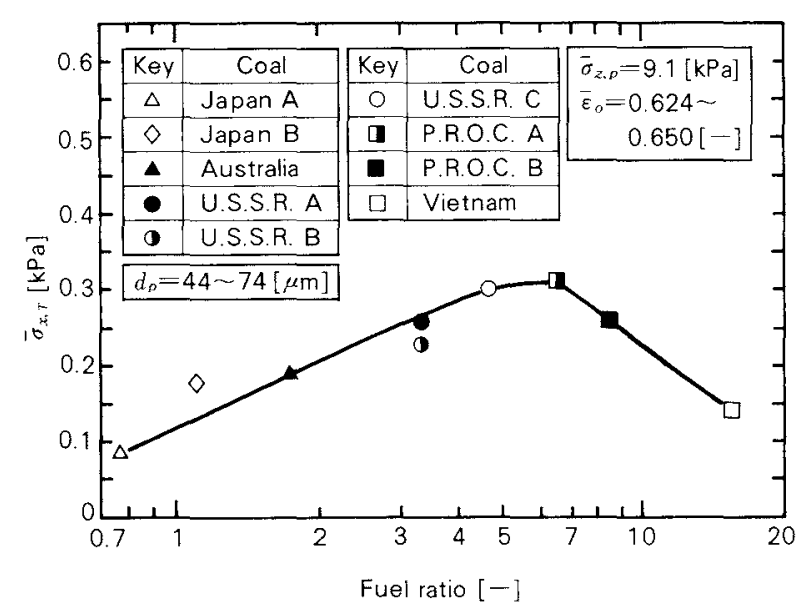

Fig. 6 Relationship between tensile strength $\bar{\sigma}_{x, T}$ and fuel ratio of fine coals varied. The flowability evaluation of fine coals on the basis of their tensile strengths will give substantially the same results as the evaluation based on their internal friction factors and shearing cohesivenesses (Fig. 5).

When the internal friction factor $\mu_{m, s}$ and tensile strength $\bar{\sigma}_{x, T}$ were plotted against the carbon content or volatile matter, the data were rather scattered. This suggests an importance of taking not only the kind of coal but also the fuel ratio (degree of coalification) into considerations on transportation, storage, supply and handling of fine coals.

\section{(2) Flowability of fly ash}

Combustion of fine coal produces approximately $20 \%$ fly ash. It is, therefore, important to evaluate also the dynamic characteristics of fly ash in combustion processes of coal.

Figure 7 shows an example of the direct shearing test results of fly ash. Coulomb's law applies to both the $\bar{\sigma}_{z, m}-\bar{\tau}_{x, s}$ relation and the $\bar{\sigma}_{z, w}-\bar{\tau}_{x, s}$ relation. There is also no significant difference between them. The applied vertical stress $\bar{\sigma}_{z, w}$ is transmitted totally to the vicinity of shearing plane. The same results were also obtained for fly ash $\mathrm{B}$ and clinker. The vertical stress distribution in the vicinity of shearing plane was confirmed to be less uneven in fly ash than in any fine coal samples.

Table 2 summarizes the internal friction factor $\mu_{m, s}$, shearing cohesiveness $\bar{C}_{m}$ and tensile strength $\bar{\sigma}_{x, E}$ of fly ashes (A and B) and clinker. These parameters are all lower than those of fine coals. Therefore, fly ash is considered to be more flowable than fine coal. The lower values of internal friction factor and tensile strength for fly ashes than for fine coals may be attributed to the loss of fixed carbon and volatile matter, and the sphericity of fly ash particles resulting from high-temperature combustion.

Figure 8 compares $\mu_{m, s}, \bar{C}_{m}$, and $\bar{\sigma}_{x, E}$ of fly ashes together with those of various other powders ${ }^{14)}$. The internal friction factor and shearing cohesiveness of fly ashes $\mathrm{A}$ and $\mathrm{B}$ are approximately intermediate between those of talc and magnesium stearate (both are lubricants). This fact implies a rather high flowability of fly ashes. 


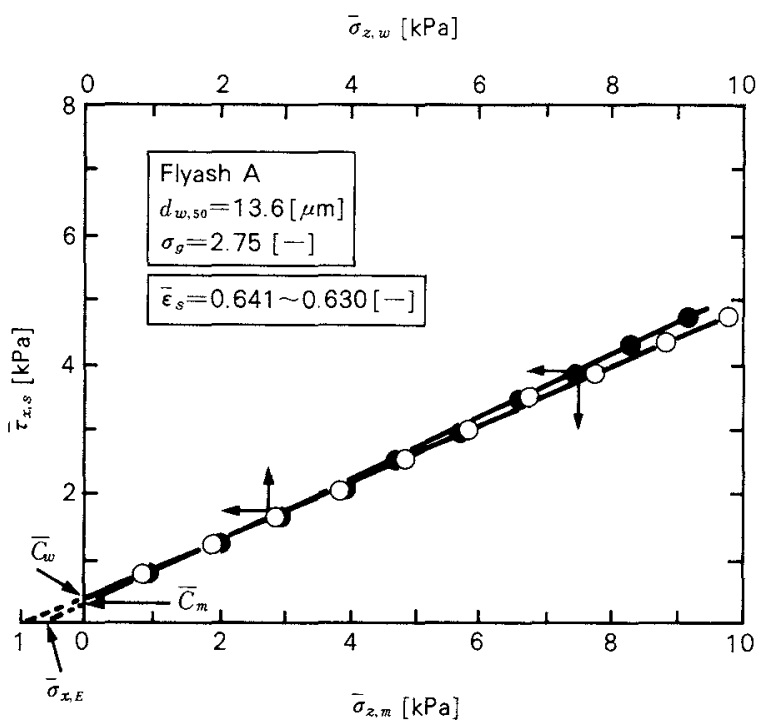

Fig. 7 Result of direct shear test for fly ash

Table 2 Comparison of $\mu_{m, s}, \bar{C}_{m}$ and $\bar{\sigma}_{x, E}$ of fly ash and those of fine coal

\begin{tabular}{l|c|c|c}
\hline Coal, Ash & $\mu_{m, s}[-]$ & $\bar{C}_{m}[\mathrm{kPa}]$ & $\bar{\sigma}_{x, E}[\mathrm{kPa}]$ \\
\hline Australia & 0.56 & 0.32 & 0.57 \\
Fly ash A & 0.47 & 0.24 & 0.52 \\
\hline Japan A & 0.58 & 0.33 & 0.57 \\
Japan B & 0.52 & 0.42 & 0.81 \\
Clinker & 0.45 & $\doteqdot 0$ & $\doteqdot 0$ \\
Fly ash B & 0.37 & 0.15 & 0.39 \\
\hline
\end{tabular}

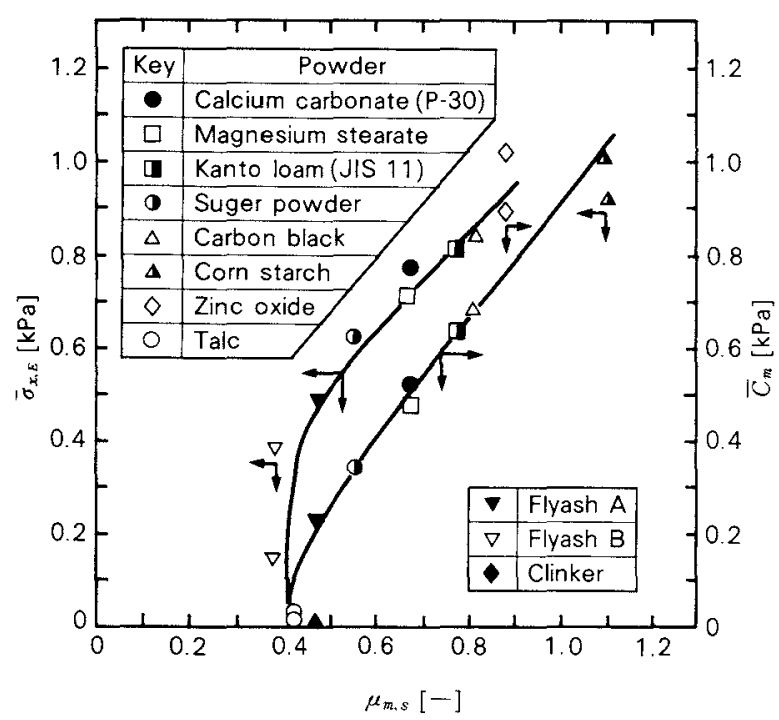

Fig. 8 Comparison of $\mu_{m, s}, \bar{C}_{m}$ and $\bar{\sigma}_{x, E}$ of fly ash and those of fine powders

\section{2 Tensile strength, internal friction factor and shearing cohesiveness of wet fine coals}

(1) Breakup process curve and packing characteristics of wet fine coals

Figure 9 shows an example of the tensile breakup process curves of wet fine coals with various water contents $\phi_{v}$ and initial void fraction $\bar{\epsilon}_{0}$. When the water content $\phi_{v}$ is low, a distinct disrupture of the coal bed occurs at a maximum tensile stress $\bar{\sigma}_{x, T}$. The tensile stress $\bar{\sigma}_{x}$ is then rapidly reduced. However, as the water content $\phi_{v}$ increases, $\bar{\sigma}_{x}$ gradually decreases without a distinct point of disrupture even after a maximum tensile stress. This is due to the effect of elongation of liquid bridges. Such a pattern of disrupture in relation to the water content was also observed in Japanese coal A and Toyoura sand ${ }^{15)}$. Defining the maximum point of tensile stress $\bar{\sigma}_{x}$ as tensile strength $\bar{\sigma}_{x, T}$, the horizontal displacement at which $\bar{\sigma}_{x, T}$ be obtained is defined as breakup displacement $\delta_{x, T}$. As shown in Fig. 9, the tensile strength $\bar{\sigma}_{x, T}$ and the breakup displacement $\delta_{x, T}$ increase with an increase in the water content. Namely, the particle cohesiveness increases with an increase in the water content. However, when $\phi_{v} \geq 42 \%$, the tensile strength decreases despite an increase in the

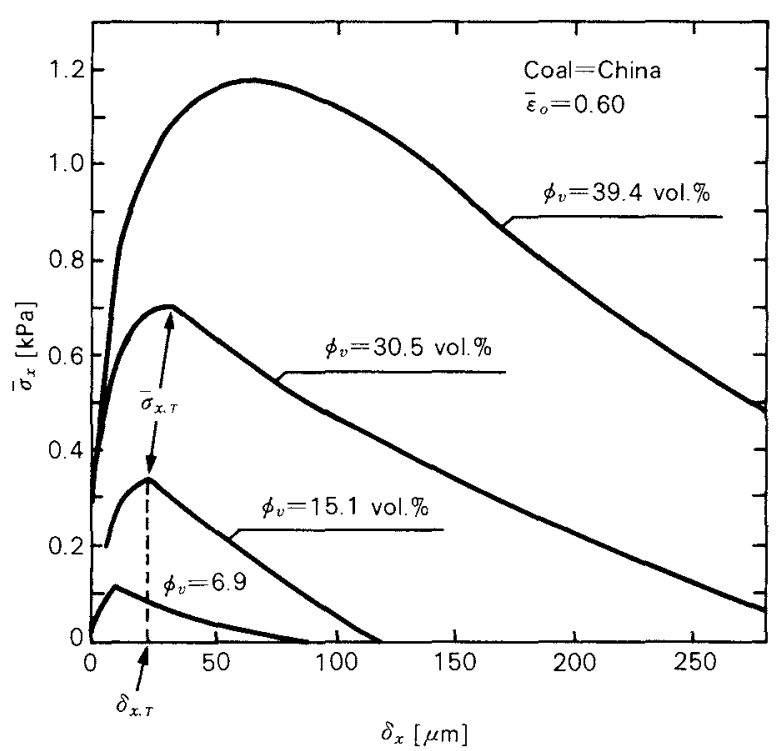

Fig. 9 Tensile breakup process curves (the relation of tensile stress $\bar{\sigma}_{x}$ versus horizontal displacement $\left.\delta_{x}\right)$ 
Wreakup displacement (this point will be discussed later).

As the initial void fraction $\bar{\epsilon}_{0}$ was decreased with a constant water content, the point of disrupture of the coal bed became more sharp and the tensile strength increased. However, the breakup displacement $\delta_{x, T}$ was not affected by the void fraction.

Figure 10 shows the relation between the breakup displacement $\delta_{x, T}$ and water content $\phi_{v}$. The data of Toyoura sand $\left(d_{p}=105 \sim\right.$ $305 \mu \mathrm{m})$ and polyvinyl chloride $\left(d_{p}=63 \sim\right.$ $177 \mu \mathrm{m})$ are also shown together for comparison ${ }^{15)}$. The breakup displacement measured 15 to 20 times in the tensile breakup tests is expressed in terms of the mean value. From the relation between the breakup displacement and water content, the packing characteristics of powder-liquid system for wet Toyoura sand have been divided into a pendular zone $\left(\phi_{v} \leq\right.$ $8 \%$ ), in which the breakup displacement $\delta_{x, T}$ increases with an increase in $\phi_{v}$, and a comixture of funicular and capillary zones in which the breakup displacement increases rapidly after passing through the funicular zone $(8<$ $\phi_{v}<26 \%$ ) where the breakup displacement

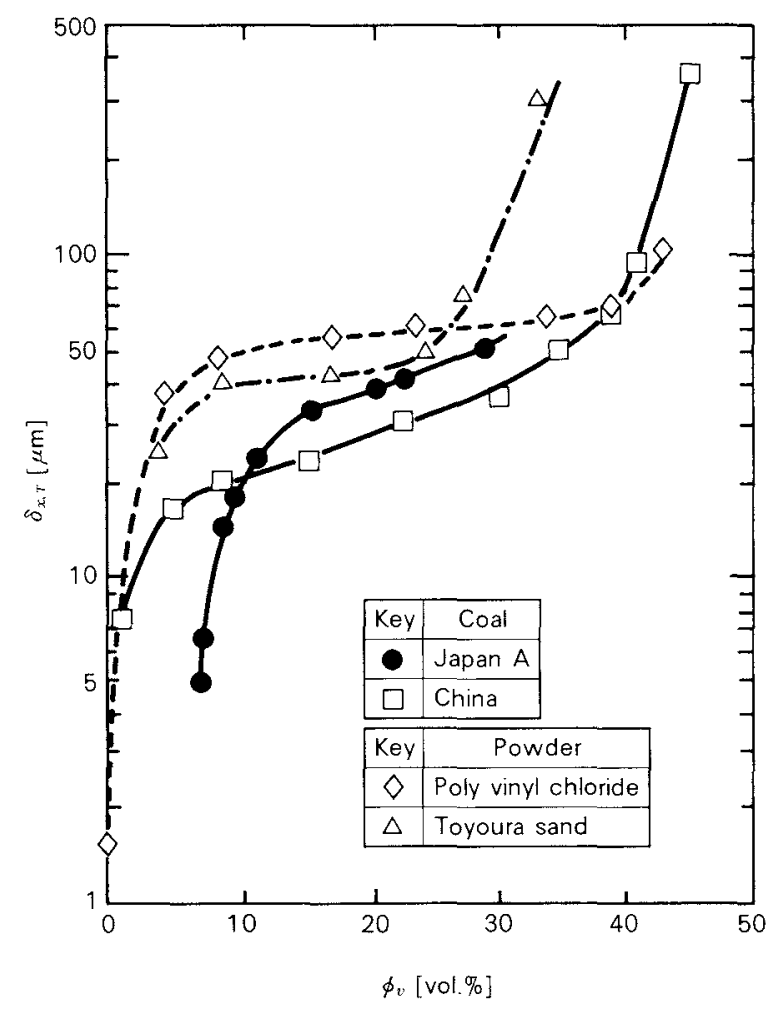

Fig. 10 Relation of breakup displacement $\delta_{x, T}$ versus water content $\phi_{v}$ remains almost constant ${ }^{15}$ ). These zones have been clearly observed also for wet polyvinyl chloride powder. On the contrary, in case of wet fine coals, the funicular zone where the water phase forms a continuum within the coal bed is ambiguous. However, for the both coal samples, the pendular zone can be identified as $\phi_{v}<10 \%$. For Chinese coal $\mathrm{A}$, the range of $10<\phi_{v}<35 \%$ seems to correspond to the funicular zone. For Japanese coal, the range of $10<\phi_{v}<20 \%$ may be identified as the funicular zone. Water contents exceeding these values may be regarded as a mixed region of the funicular and capillary zones. The difficulty in determining the packing characteristics of wet coal systems, as compared to other powders like Toyoura sand, is probably due to penetration of the added water into porous coal particles.

(2) Tensile strengths of fine coal and fly ash in a wet state

Figure 11 shows an example of the tensile strength of wet fine coals with various water contents $\phi_{v}$ and initial void fractions $\bar{\epsilon}_{0}$. The tensile strengths of wet fine coal beds with the water content $\phi_{v} \leq 6.5$, are too small to be measured and shown in this figure, since almost all the water added penetrates into coal particles. At the water contents below $6.5 \%$, the flowability of fine coals seems to be little affected by the water content. At $\phi_{v}=6.5$, adsorption of water on the particle surface induces formation of liquid bridge to result in a rapid increase in the tensile strength with an increase in the water content due to bridgeinduced adhesion of particles (pendular zone, $\left.\phi_{v} \leq 9.5\right)$. When $11.1<\phi_{v}<21 \%$, the tensile strength increases (funicular zone), because liquid bridge formation is further enhanced by an increased water content. With a further increase in the water content, the tensile strength is saturated (comixture of the funicular and capillary zones), because the water content exceeds the limit at which coal particles no longer can hold liquid. At any $\phi_{v}$, the tensile strength is high when the initial void fraction is low. This may be due to increased contact points of particles and fusion of liquid films.

On the basis of the data shown in Fig. 11, the tensile strengths at the same void fractions are plotted against the water content $\phi_{v}$ in 


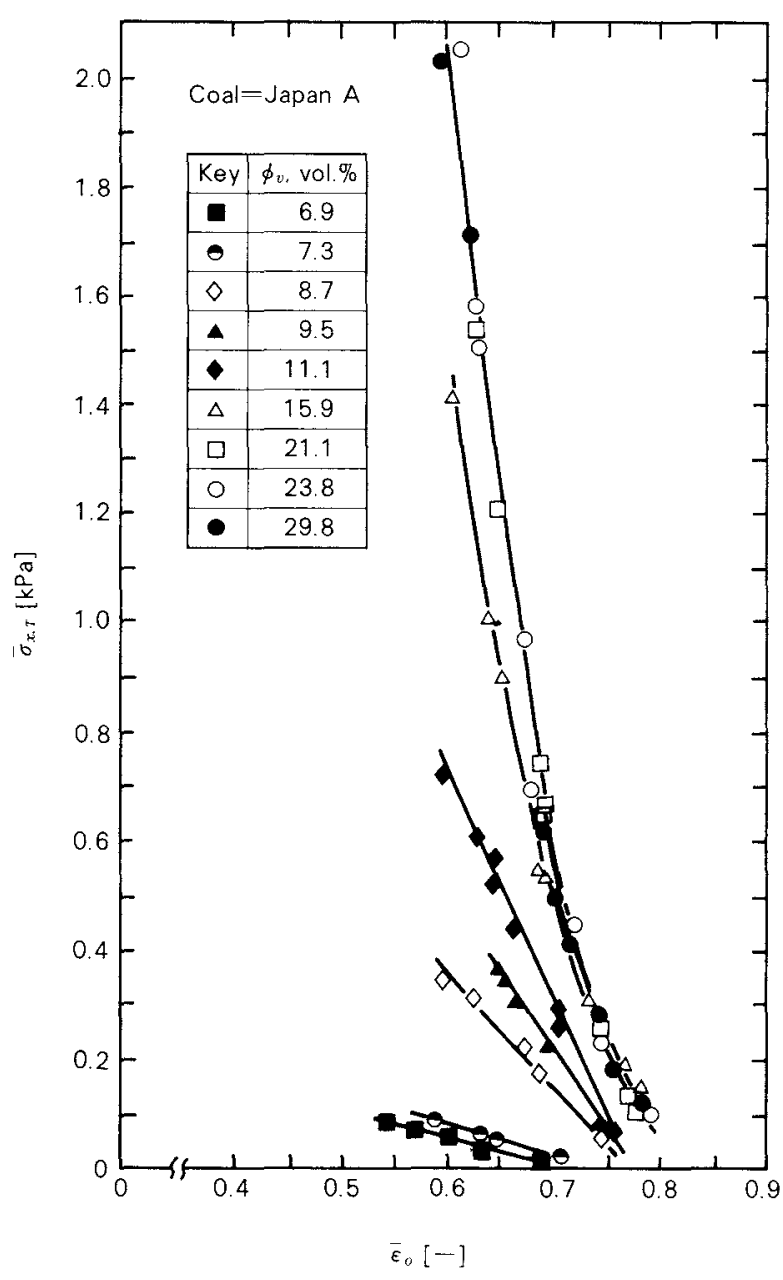

Fig. 11 Measured values of tensile strength $\bar{\sigma}_{x, T}$

Fig. 12. The data of Toyoura sand and polyvinyl chloride powder with different water contents are also shown together for comparison. As shown in Fig. 12, the tensile strength of Chinese coal $\mathrm{A}$ is found to get a larger increase at low $\phi_{v}$ (pendular zone). As $\phi_{v}$ increases, it continues to increase rather slowly and monotonically (funicular zone) and reaches a maximum at $\phi_{v}=38 \%$ (comixture of the funicular and capillary zones). A further increase in $\phi_{v}$ gives a decrease in the tensile strength, because the water content exceeds the limit at which coal particles can no longer hold the water added. The rate of increase in the tensile strength with $\phi_{v}$ is lower for Chinese coal A (semibituminous coal) than for Japanese coal A (brown coal). This may be attributable to a smaller inner surface area, smaller porosity (the ratio of capillaries and pores to total volume of particle) ${ }^{16)}$ and lower wettability of Chinese coal A. It can be noted that the flowability of

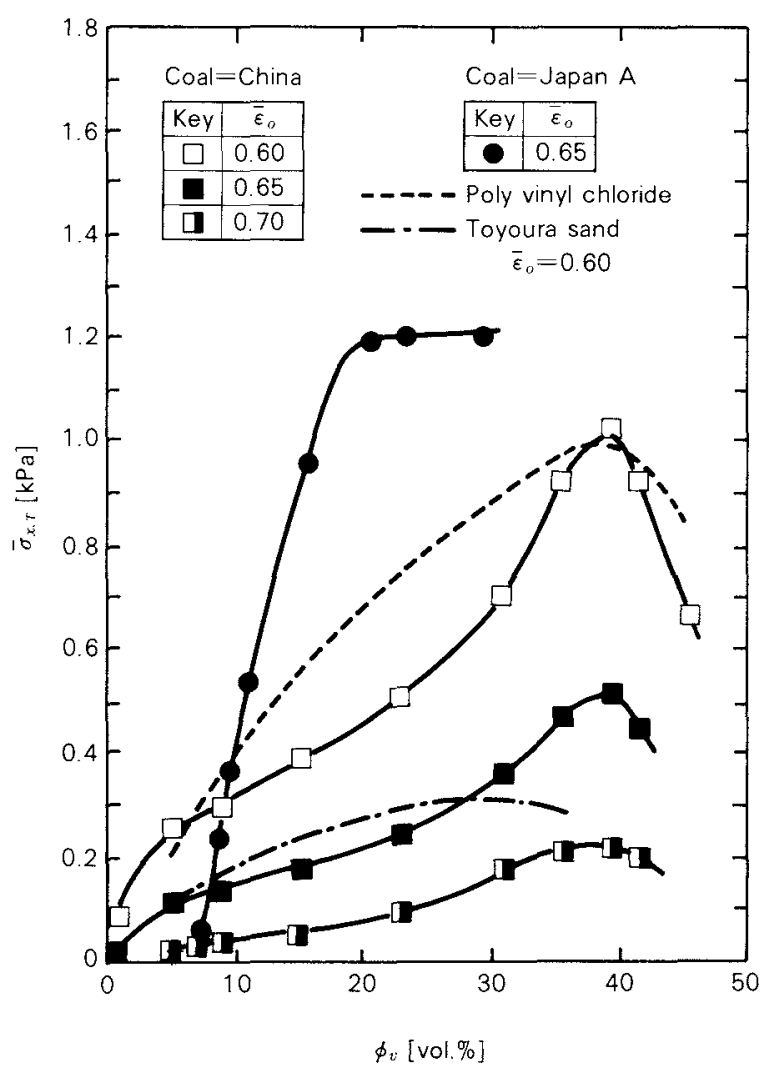

Fig. 12 Relation of tensile strength $\bar{\sigma}_{x, T}$ versus water content $\phi_{v}$

brown coals such as the sample used (Japan A) may be significantly influenced by a small change in water content. Therefore, in efficient handling of the coals with a low degree of coalification, a determination of the water content plays an important role.

Figure 13 gives an example of the effects of aging period (the elapsed time after addition of water) on the tensile strength - water content relations. When aged after addition of water, the tensile strength of wet fine coal in the pendular to funicular zones $\left(6.9<\phi_{v}<21 \%\right)$ is lowered. This may be due to the volume diminution of liquid bridge resulting from partial penetration of water into coal particles during the period of aging. Therefore, prolongation of aging period may improve the flowability of wet fine coals. This fact coincides with the phenomena that a higher flow rate in a cone hopper is obtained for the coals stored for a long time after addition of water ${ }^{7)}$. This kind of improvement of the flowability has also been observed in green mold sands (silicabentonite-water system) ${ }^{21)}$. These findings 


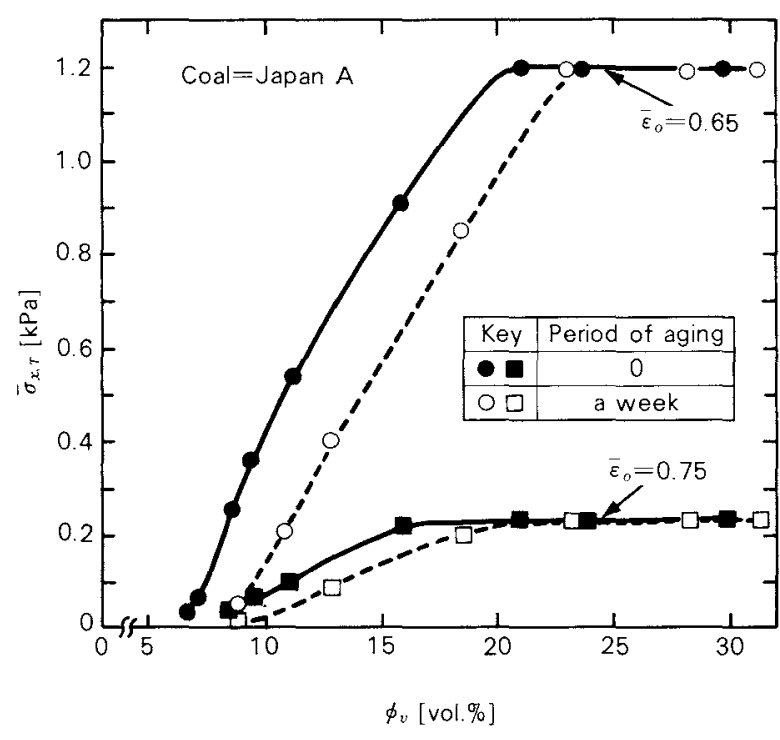

Fig. 13 Relation between tensile strength and water content after varying the period of aging (period after addition of water)

verify that the flowability of fine coals is controlled by the water adsorbed onto the surface of coal particles.

Prolongation of the aging period of two weeks produced no difference in the results. The tensile strength of wet Chinese coal A was less affected by aging, because of its smaller inner surface area and porosity.

The measured values of tensile strength of wet fly ash and fine coal are shown in Fig. 14. Clinker ash gives the same value of tensile strength as its original material. On the other hand, the tensile strength of fly ash is less than that of fine coal at $\bar{\epsilon}_{0}=0.65$. The lower value of the tensile strength of wet fly ash compared to that of fine coal may be due to the disappearance of fixed carbon and volatile matter during high-temperature combustion and also to sphericity (surface smoothness) of ash particles, as previously described. From Fig. 14, the tensile strength of fly ash is found to increase with a very slight increase in the water content. This level of water content is within a range which is subject to be easily changed by the relative atmospheric humidity of 40 to $80 \%$. This fact indicates that the flowability of fly ash is affected by climatic and seasonal humidity changes.

(3) Internal friction factor and shearing cohesiveness of wet fine coals

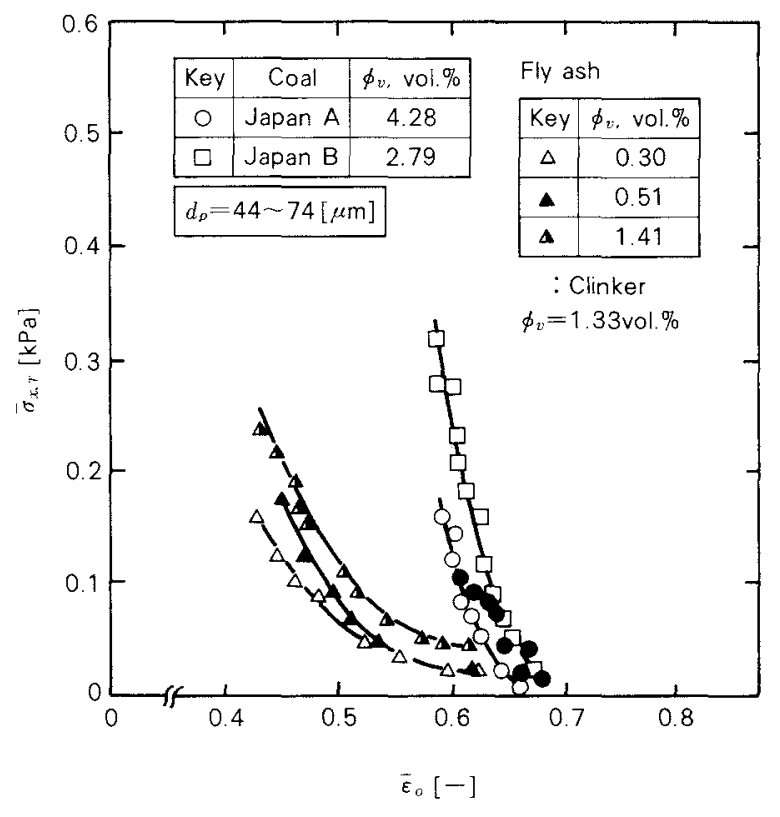

Fig. 14 Measured values of tensile strength of wet finel coal

Figure 15 shows the internal friction factor $\mu_{m, s}$ and shearing cohesiveness $\bar{C}_{m}$ in relation to the water content $\phi_{v}$, as measured by the constant-load, direct shearing test. The internal friction factor of Japanese coal A remains constant when $\phi_{v} \leq 6.5$ and increases when $6.5<$ $\phi_{v}<10 \%$. At the water content exceeding this range, it again becomes constant after a slight decrease. On the other hand, the shearing cohesiveness is immeasurably small when $\phi_{v} \leq$ $6.5 \%$, but increases with the water content over $6.5 \%$. This indicates a reduction of the flowability by an increase in water content above $6.5 \%$. This agrees with the flowability evaluation by actual experiences of handling wet fine coals. The same level of the internal friction factor and shearing cohesiveness of coals at $\phi_{v}$ of up to $6.5 \%$ as dry coals, coincides with the measurement results of dry coals described in subsection 3.2 (1). It has also been verified by the direct shear tests that Japanese coal $\mathrm{A}$ in a wet state has approximately the same flowability as dry coal when $\phi_{v}$ is $6.5 \%$ or below. Figure 15 also shows that the internal friction factor of Chinese coal $\mathrm{A}$ increases monotonically with an increase in the water content, when the water content $0<\phi_{v}<15 \%$. At $15<\phi_{v}<20 \%$, the internal friction factor decreases. On the other hand, the shearing cohesiveness increases with an increase in the 


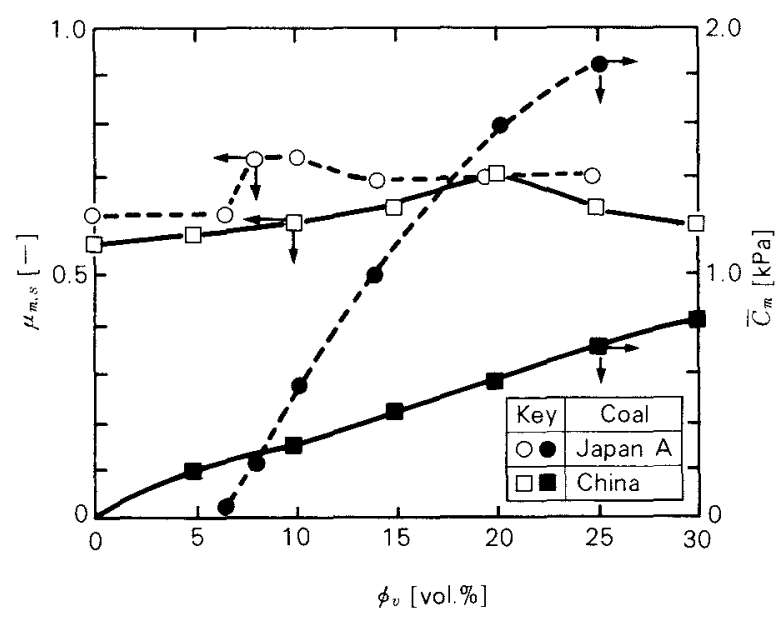

Fig. 15 Relations of internal friction factor $\mu_{m, s}$ and shearing force $\bar{C}_{m}$ versus water content

water content. This tendency is similar to the $\bar{\sigma}_{x, T}-\phi_{v}$ relation (Fig. 12). The ranking of the sample coals by their shearing cohesiveness does not conflict with that by their tensile strengths. No significant difference is also noted between $\bar{C}_{m}$ and $\bar{\sigma}_{x, T}$ themselves. These findings suggest that the flowability of fine coals in a wet state may be better evaluated by the shearing cohesiveness and tensile strength rather than by the internal friction factor.

\section{Conclusion}

Close correlations have been confirmed between the dynamic properties (internal friction factor, shearing cohesiveness and tensile strength) and fuel ratio of fine coals. The ranking of flowability of fine coals is in order of brown coal, bituminous coal and semibituminous coal. The flowability of semianthracite and anthracite is high. The flowability evaluation based on the dynamic parameters coincides with the empirical scoring of flowability based on the flow-rate from a hopper or on actual experiences of handling fine coals. Compared to fine coals, fly ash shows a higher flowability with lower values of both the internal friction factor and shearing cohesiveness.

The tensile strength of wet fine coals increases with an increase in the water content in the pendular to funicular zones, but becomes constant or shows a maximum in comixture of the funicular and capillary zones, and finally decreases with further increase in the water content. Brown coal, which has a larger inner surface area and wettability shows a significantly larger increase of tensile strength with an increase in the water content, when compared to semibituminous coal. The flowability of wet fine coals can be better evaluated by the tensile strength and shearing cohesiveness rather than by the internal friction factor. Protraction of the aging period (time after addition of water) results in a higher flowability, because partial penetration of the added water into coal particles reduces the tensile strength. This indicates that the flowability is controlled by water adsorbed onto coal particles. The flowability of fly ash is easily affected by climatic and seasonal humidity changes.

\section{Nomenclature}

$\bar{C}_{m}$ : shearing cohesiveness, defined by Eq. (2) (Fig. 2)

$\bar{C}_{w}$ : shearing cohesiveness, defined by Eq. (1) (Fig. 2)

$F R$ : fuel ratio of coal

$n$ : shear index, defined by Eq. (1)

$\delta_{x}:$ horizontal displacement of powder bed under tensile test

$\delta_{x, T}:$ horizontal displacement at which tensile strength $\bar{\sigma}_{x, T}$ is obtained (Fig. 9) $\quad[\mu \mathrm{m}]$

$\delta_{z}$ : vertical displacement of powder bed under direct shear test

$\bar{\epsilon}_{0}$ : initial void fraction of powder bed under tensile or shear test

$\phi_{v}$ : volumetric water content in powder bed [-]

$\mu_{m, s}$ : internal friction factor, defined by Eq. (2)

$\bar{\sigma}_{x}$ : horizontal or tensile stress in powder bed under tensile test

$\bar{\sigma}_{x, E}$ : tensile stress defined by Eq. (2) with $\bar{\tau}_{x, s}=0$ (Fig. 2)

$\bar{\sigma}_{x, T}:$ tensile strength of powder bed (Fig.9)

$\sigma_{z, m}$ : vertical stress in the vicinity of shearing plane, measured at points, $F, O, R$ (Fig. 1)

$\sigma_{z, m^{\prime}}$ : vertical stress in the vicinity of shearing plane, measured at points $F^{\prime}, O^{\prime}, R^{\prime}$

(Fig. 1)

$\bar{\sigma}_{z, m}:$ mean vertical stress in the vicinity of shearing plane

$\bar{\sigma}_{z, w}:$ applied vertical stress to powder bed under direct shear test (Fig. 1)

$\bar{\tau}_{x}$ : shearing stress in powder bed under direct shear test

$\bar{\tau}_{x, s}$ : stationary shearing stress in powder bed under direct shear test 


\section{WReferences}

1) Tanaka, K., G. Hida and K. Imatani: Sentan, 12, 366 (1962).

2) Honma, J., M. Yamamoto, H. Iwata and K. Masuda: J. Fuel Soc., Japan, 45, 851 (1962).

3) Carr, J. F. and D. M. Walker: Powder Technology, 1, $369(1967 / 68)$.

4) Aoki, R. and H. Tsunakawa: J. Soc. Materials Sci. Japan, 18, 497 (1967).

5) Jayasinghe, S. S. and N. Pilpel: J. Inst. Fuels, Feb., 51 (1970).

6) Shinohara, K. and T. Tanaka: J. Chem. Eng., Japan, 8, 50 (1975).

7) Aoki, R. and S. Yasuda: J. Soc. Powder Tech., Japan, 14, 390 (1977).

8) Arakawa, M.: J. Soc. Materials Sci., Japan, 30, 878 (1981).

9) Aoki, R.: Preprint of the 48th Annual Meeting of Soc. Chem. Eng., Japan, p. 373 (1983).

10) Tsunakawa, H.: J. Soc. Powder Tech., Japan, 20, 554 (1983).

11) Murata, H., M. Wakabayashi and T. Egusa: ibid., 20, 558 (1983).
12) Terashita, K., K. Miyanami, T. Yano and Y. Yamamoto: ibid., 15, 583 (1978).

13) Terashita, K., K. Miyanami, T. Yano and S. Iwasawa: ibid., 17, 373 (1980).

14) Terashita, K., K. Miyanami, M. Tanigawa and S. Iwasawa: ibid., 18,896 (1981).

15) Terashita, K., K. Miyanami, T. Konishi and J. Yoshida: J. Soc. Materials Sci., Japan, 30, 873 (1981).

16) Kimura, H. and S. Fujii: "Sekitan-Kagaku to Kogyo", p. 58, Kyoritsu Shuppan, Co. (1977).

17) Schwedes, J.: Powder Technology, 11, 59 (1975).

18) Terashita, K., Y. Yamamoto, M. Tanigawa, K. Miyanami and T. Yano: J. Soc. Materials Sci., Japan, 29, 876 (1980).

19) Ashton, D., C. Cheng, R. Farley and F.H. Valentin: Rheological Acta, 4, 206 (1965).

20) Terashita, K., K. Miyanami, T. Konishi and K. Furubayashi: Preprint of the 14th Fall Meeting of Soc. Chem. Eng., Japan, p. 389 (1980).

21) Terashita, K., T. Kimura, E. Tsukaguchi and K. Miyanami: J. Soc. Powder Tech., Japan, 20, 733 (1983). 